\title{
Oral Status and the Facial Transplant Patient (Letter to the Editor)
} Yüz Nakli Hastaları ve Oral Durum (Editöre Mektup)

\author{
Hasan Hatipoğlu', Müjgan Güngör Hatipoğlư \\ ${ }^{1}$ Dumlupinar University, Faculty of Dentistry, Periodontology, Kütahya, Turkey; ${ }^{2}$ Dumlupınar Üniversitesi, Faculty of Dentistry, \\ Dentomaxillofacial Radiology, Kütahya, Turkey
}

\section{Dear Editor,}

Recent developments in plastic surgery are very exciting. Total or partial face transplantation procedures are very difficult and not without complications. We know that the patient selection and planning of the procedures are carefully and very well planned ${ }^{1}$. As a part of the body and face region, we believe that some issues of dental status should be considered before planning and treatment in such a difficult surgery.

A number of dental recommendations are suggested for organ transplant candidates. However, there is not a consensus between organ transplantation centers. It is arguable that dental diseases are sources of infectious complication after the transplantation procedures ${ }^{2}$. Thus a special attention should be given for existing oral-dental statuses for the facial transplantation candidates.

Limited literatures discuss about preliminary dental imaging, examinations and treatments in pre- or post-transplantation period or dental treatment need in this patients ${ }^{3-5}$.

Oral cavity, exhibit a close connection with facial transplant area. It is clear that patients are more susceptible to infections and trauma after the transplantation. Infections from oral origin may have negative effects for the immunocompromised patients and recipient transplant area in the post transplantation period. Additionally, oral surgeries (e.g. dental extraction) or prolonged dental procedures can lead to a physical trauma to the transplanted face. The need for dental clinical and radiological evaluations and treatment in the pre transplant phase seems to be more critical especially in this condition.

Even with the limited number of total or partial facial transplant cases, we believe that a treatment protocol should be established for dental therapies in this patient group. With this protocol, possible treatment approaches for dental conditions (in pre- or post-transplantation periods) can be determined. Our belief is that such a crucial and high risk procedure should be supported with a carefully examination and elimination of active dental diseases and potential infection sources of oral origin. The close relationships of the transplant area with the oral cavity need a special cooperation between plastic surgeons and dental health professionals.

Keywords: dentistry; oral health; facial transplantation

\section{References}

1. Pomahac B, Nowinski D, Diaz-Siso JR, et al. Face transplantation. Curr Probl Surg 2011;48(5):293-357.

2. Guggenheimer J, Eghtesad B, Stock DJ. Dental management of the (solid) organ transplant patient. Oral Surg Oral Med Oral Pathol Oral Radiol Endod 2003;95(4):383-9.

3. Bueno EM, Diaz-Siso JR, Pomahac B. A multidisciplinary protocol for face transplantation at Brigham and Women's Hospital. J Plast Reconstr Aesthet Surg 2011;64(12):1572-9.

4. Losee JE, Fletcher DR, Gorantla VS. Human facial allotransplantation: patient selection and pertinent considerations. J Craniofac Surg 2012;23(1):260-4.

5. Lantieri L, Meningaud JP, Grimbert P, et al. Repair of the lower and middle parts of the face by composite tissue allotransplantation in a patient with massive plexiform neurofibroma: a 1-year follow-up study. Lancet 2008;372(9639):639-45. 